\title{
MANAGEMENT OF LOWER URINARY RETENTION IN A LIMITED RESOURCE SETTING
}

\author{
Ugare U .G ${ }^{1}$, Ima-Abasi Bassey $^{2}$, Udosen E .J ${ }^{1}$, Akanimo Essiet ${ }^{1}$, O. O Bassey ${ }^{1}$
}

\begin{abstract}
BACKGROUND: There is a projected increase in lower urinary tract obstruction by 2018, especially in the developing economies of Asia and Africa. However in many of these countries, the problems encountered both by the patients and the clinicians are not well documented. Our aims are, to prospectively analyse the management of urinary retention, the associated difficulties, and complications in our setting, where access to investigative modalities such as Computerize Tomography and Magnetic Resonance Imaging are not available.

PATIENTS AND METHODS: The study was approved by the University Of Calabar Teaching Hospital ethical committee. A validated Proforma was used to collect data from all patients who were clinically diagnosed with urinary retention based on history, and physical examination, from July 2009 to June 2010. Data collected from the 1st of July 2009 to the 30th of June 2010, include demographics, findings on physical examination, previous medical history and co-morbid conditions. The results of investigations done such as: urinalysis, full blood count, electrolytes, urea and creatinine, intravenous urography, trans- abdominal ultrasonography, chest $X$-ray and histology of trans-rectal biopsies of the prostate. The total number of new patients seen, including those with urinary retention during the study was documented. The retentions were also classified into acute and chronic. All the patients were followed up throughout the study. The data was analysed using Epi-Info statistical program version 3.4 of 2007 to analyse the data, estimating averages, mean, median and percentages. RESULTS: The total number of new patients seen, including those with urinary retention was Seventy thousand, one hundred and thirty nine (70,139). Of this number, hundred and fifty nine $(0.23 \%)$, presented with urinary retention; 145 (91.2\%) were acute, and14 (8.8\%) were chronic. The male: female ratio was 39:1.The patients ages ranged from 4 to 94 years, with a mean of 53.7 \pm 11.2 . Seventy seven [48.4\%] of them were in the $6^{\text {th }}$ and $7^{\text {th }}$ decades of life. The common causes were; prostatic diseases [BPH and cancer of the prostate] $77.0 \%$, infections $75.8 \%$, trauma $12.1 \%$, and congenital $12.1 \%$. Urinary retention was relieved by: indwelling urethral catheterization [IUC] 120 patients (75.5\%), supra- pubic cystostomy [SC] 34 (21.4\%) and intermittent urethral catheterization [IC] 5 (3.1\%). The most frequently encountered complications include pyuria (18.2\%), pericatheter sepsis $17.5 \%$, and haemorrhage during change of catheter 16.8\% [figure 2].

CONCLUSION: Lower urinary retention is common in our environment. The management is appropriate and standard. The man power and facilities are inadequate, and requires urgent improvement.

KEYWORDS: Urinary retention; management; limited resources
\end{abstract}

DOI: http://dx.doi.org/10.4314/ejhs.v24i4.8

\footnotetext{
${ }^{1}$ Department of Surgery, University of Calabar Teaching Hospital, Calabar, Nigeria

${ }^{2}$ Dept of Pathology University of Calabar Teaching Hospital, PMB 1278 Calabar, Nigeria

Corresponding Author: Ugare UG, Email: ugareudeygabrieldr@yahoo.com
} 


\section{INTRODUCTION}

Urinary retention [UR] is an impaired ability to micturate due either to a mechanical or functional obstruction of the lower urinary tract $(1,2)$. It is a common urological problem, seen often in men than women by a ratio of 10:1 (3). The explanation for the high frequency of this problem in males, is the presence of the prostate gland. Pathologies resulting from this gland, account for more than $50 \%$ of all the cases of lower urinary tract obstruction and urinary retention in males $(4,5)$

Other causes of lower urinary retention in both males and females include neoplasms, trauma, strictures, valves, and acute inflammation of the lower urinary tract (5- 7). Damage to the nerves that supply the bladder, spinal cord trauma and neoplasms of the spinal cord either primary or secondary; will produce functional obstruction (8, $9,10)$. Urinary retention may be acute [presenting with severe pain] or chronic [usually painless] (1, $2,11,12)$. However neurogenic retention even of sudden onset, is usually painless.

The overall incidence of urinary retention [both acute and chronic] globally, is not known. Most of the reported incidences or prevalences are from studies conducted on acute retention, in patients with benign prostatic hyperplasia [BPH] and prostate cancer $[\mathrm{CaP}](1,3,7,11)$.

A recent report by the British Journal of Urology (12) estimates that by 2018 both the incidence and prevalence of lower urinary tract symptoms, and bladder outlet obstruction will increase by $20 \%$, with Africa and the Asian countries experiencing the steepest increase Previous studies have put the incidence of lower urinary retention between $2.7 \%$ and $42 \%$. Pickard et al (11) reported that acute urinary retention occurred in $42 \%$ of men undergoing prostatectomy in North America and Britain, while Ekwere et al (10) reported a 35\% incidence among 145 prostate cancer patients. The report by Minardi et al (13) put it between $2.7 \%$ to $29 \%$ in women. The importance of urinary retention in patient care is that a delay in relieving the obstruction, may lead to severe complications such as hydroureters, hydronephrosis and ultimately renal failure (14, 15). More than $60 \%$ of cases of lower urinary retention can be diagnosed from clinical history and physical examination. A few cases will however require diagnostic imaging such as simple pressure voiding studies, transabdominal ultrasonography, endoscopic visualisation and multichannel videourodynamic studies $(1,2,6)$.

Because of the painful nature of acute retention, and the complications that may result from any form of retention, and the impact on the patient's quality of life; the initial management is usually an emergency. Urethral catheterization is the quickest and most frequently employed method (1). Other methods include suprapubic cystostomy, urethral bouginage with or without catheterization, and rarely bladder aspiration $(1,3$, 7). Most of these methods are associated with complications such as pain, urethral trauma, haemorrhage, pericatheter urethritis, septic shock and catheter retention (], 7, 8, 16). These complications can be minimised through a protocol guided relief of retention, trained manpower, using the appropriate size of catheters with respect to the age of the patient, regular change of catheter and the use of antibiotic impregnated or silastic catheters $(1,17,18)$.

Our objectives were to assess the causes of urinary retention, methods of relief, associated complications and the problems encountered in the process of management, in our setting of limited resources such as video-assisted Urodynamic studies, CT scan and other modern imaging modalities.

\section{PATIENTS AND METHODS}

This prospective study was approved by the University of Calabar Teaching Hospital ethical committee. A Proforma was used to collect data from all patients who were diagnosed with urinary retention from the clinical history and physical examination, from July $1^{\text {st }} 2009$ to June $30^{\text {th }}$ 2010.The data collected include demographics, past medical history, co-morbid conditions, results of investigations done such as urinalysis, full blood count, electrolytes, urea and creatinine, fasting blood sugar [for patients in the $6^{\text {th }}$ decade and above], intravenous urography, transabdominal ultrasonography, chest X-ray, and histology of biopsy specimen. Patients who were referred from other centres, and have already been commenced on treatment, and those seen before the commencement of the study were excluded. All the patients were followed up throughout the period of the study. At the end of the study period, the data was analysed using EPI-Info statistical 
programme version 3.4 .3 of 2007 by the CDC, USA.

\section{RESULTS}

The total number of new patients, including those who had urinary retention seen was Seventy thousand, one hundred and thirty nine $(70,139)$. One hundred and fifty-nine, $(0.23 \%)$ of them presented with lower urinary retention. Ninety six $(60.4 \%)$ of them were seen at the emergency department, while $63(39.6 \%)$ presented at the Urology clinic. One hundred and forty five, (91.2\%) were acute retention, and 14 (8.8\%), chronic retention. Of the one hundred and fifty nine patients, only four were females, giving a male: female ratio was of approximately 39:1. Table 1 showed the age distribution of patients. Majority were in the 61-80 years age group [39.6\%], followed by persons in the 40-60 years age bracket $35.8 \%$. Only three females presented with lower urinary retention, giving a male: female ratio of 53:1.
Table 1: The age distribution of patients in the study

\begin{tabular}{|c|c|c|c|}
\hline \multicolumn{4}{|c|}{ Age range $[n=159]$} \\
\hline & Total[\%] & $\mathbf{M}[\%]$ & $\mathbf{F}[\%]$ \\
\hline $0-20$ & $6[3.8]$ & $5[3.1]$ & $1[0.6]$ \\
\hline $21-40$ & $26[16.4]$ & $25[15.7]$ & $1[0.6]$ \\
\hline $41-60$ & $58[36.5]$ & $57[35.8]$ & $1[0.6]$ \\
\hline $61-80$ & $63[39.6]$ & $63[39.6]$ & - \\
\hline$>81$ & $6[3.8]$ & $6[3.8]$ & - \\
\hline Total & $159[10$ & $156[98.1]$ & \\
\hline
\end{tabular}

The age distribution is shown in Table1. It ranged from 4 to 94 years, with a mean of $53.7 \pm 11.2$. Seventy seven [48.4\%], of them were in the $6^{\text {th }}$ and $7^{\text {th }}$ decades of life.

Table2: Shows causes of retention, methods of relief of retention

\begin{tabular}{|c|c|c|c|c|c|}
\hline cause of retention & $\begin{array}{l}\text { Frequency } \\
\text { [\%] }\end{array}$ & methods of relief & $\begin{array}{l}\text { frequency } \\
{[\%]}\end{array}$ & $M$ & $\boldsymbol{F}$ \\
\hline $\begin{array}{l}\text { BPH[benign prostatic } \\
\text { hyperplasia] }\end{array}$ & $56[34.1]$ & $\begin{array}{l}\text { Indwelling urethral } \\
\text { catheterization }\end{array}$ & $100\left[\begin{array}{ll}6 & 2.9\end{array}\right]$ & $4[2.5]$ & $1[0.6]$ \\
\hline Carcinoma of the prostate & $41(25.0)$ & Suprapubic cystostomy & $41[25.8]$ & $24[15.1]$ & $2[1.3]$ \\
\hline Urethral stricture & $16[10.1]$ & $\begin{array}{l}\text { Bouginage + Urethral } \\
\text { catheterization }\end{array}$ & $12[7.5]$ & $57[35.8]$ & $1[0.6]$ \\
\hline Spinal cord injury & $8[5.0]$ & $\begin{array}{l}\text { Intermittent Urethral } \\
\text { catheterization }\end{array}$ & $4[2.5]$ & $56[35.2]$ & \\
\hline $\begin{array}{l}\text { RTA (with blunt abdominal. } \\
\text { Injury) }\end{array}$ & $4[2.5]$ & Interval urethral catheterization & $2[1.3]$ & $4[2.5]$ & \\
\hline $\begin{array}{l}\text { Postoperative clot } \\
\text { Postoperative. Pain }\end{array}$ & $\begin{array}{l}4[2.5] \\
4[2.5]\end{array}$ & & & & \\
\hline Acute prostatitis & $4[2.5]$ & & & & \\
\hline Acute urethritis & $3[1.9]$ & & & & \\
\hline Generalised tetanus & $3[1.9]$ & & & & \\
\hline Urethral trauma & $2[1.3]$ & & & & \\
\hline Posterior urethral values & $2[1.3]$ & & & & \\
\hline Bladder calculus & $2[1.3]$ & & & & \\
\hline $\begin{array}{l}\text { Hypospadia with meatal } \\
\text { stenosis }\end{array}$ & $2[1.3]$ & & & & \\
\hline $\begin{array}{l}\text { TB[tuberculosis of lumbers] } \\
\text { spine }\end{array}$ & $1[0.6]$ & & & & \\
\hline Bladder neck cont. & $1[0.6]$ & & & & \\
\hline
\end{tabular}


Table two shows the causes of retentions and how they were relieved. The causes of retention were:benign prostatic hyperplasia[BPH] $56[34.1 \%]$,carcinoma of the prostate[CaP] 41 [25.0\%] urethral stricture 16 [10.1\%] spinal cord injury 8 [5.0\%] road traffic accident[RTA] 4 [2.5\%]:postoperative clot, postoperative pain, acute prostatitis, acute urethritis, generalised tetanus, blunt urethral trauma, and posterior urethral valves constitute 22 [13.9\%]. Eight patients [19.5\%], with prostate cancer, presented with paraparesis of the lower limbs. One female patient presented with retention from pelvic fracture, and a second from generalised tetanus.

One hundred and twenty patients $(75.5 \%)$ were relieved with indwelling urethral catheterization [IUC], in $12(7.5 \%)$, IUC was preceded by bouginage. Thirty four patients $(21.4 \%)$ had supra pubic cystostomy [SC], and 5 (3.1\%) had intermittent urethral catheterization[IC]. By the last day of the study, the duration of catheterizing all the patients, excluding those who were placed on IC, ranged from 5 to 125 days, with an average of 37 days. Sixty-five [40.9\%] of the patients were still being catheterized at the end of the study. Twenty-five patients [44.6\%] with BPH and 17[10.7\%] with carcinoma of the prostate $[\mathrm{CaP}]$ were placed on trial without catheter [TWOC] after 3-4 weeks of medical therapy.

Table 3: Problems of managing urinary retention in UCTH

\begin{tabular}{|lc|}
\hline Problem & Percent \\
\hline Patient's lack of insight of the problem & $25 \%$ \\
Inability to keep clinic appointments & $36 \%$ \\
Poor peri-catheter hygiene & $45 \%$ \\
Difficulty in obtaining the appropriate ware[eg catheter] & $17 \%$ \\
Inability to purchase prescribed drugs & $40 \%$ \\
\hline
\end{tabular}

Table 3 shows that $36.0 \%$ could not fulfil clinic appoints, $40.0 \%$ were unable to purchase their prescribed drugs ,45\% had poor peri catheter hygiene and $25.0 \%$ lack insight of their condition In $17 \%$ the right size of urethral cather could not be obtained. Table 3 showed the problems encountered these included: inability to keep clinic appointments, difficulty in obtaining the appropriate catheter size with respect to the patient's age, and inability to purchase prescribed drugs. 
Figure 1: Procedures used and number of patients on definitive treatment by the $12^{\text {th }}$ month of the study $n==128[80.5 \%]$

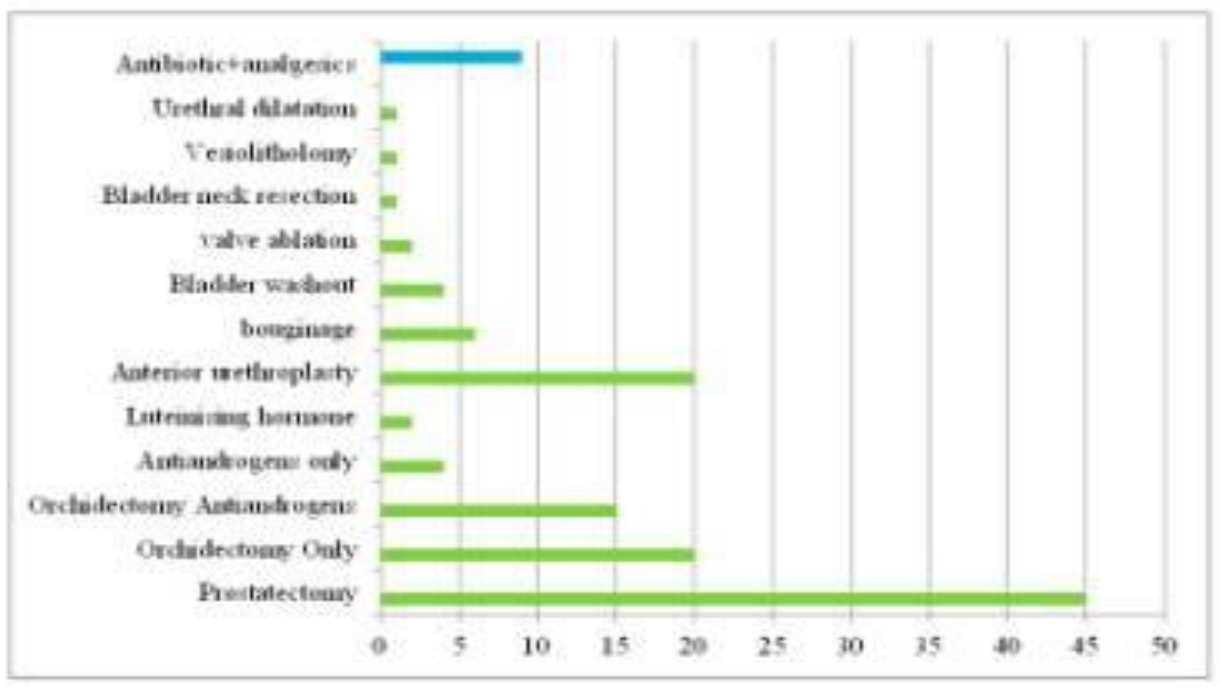

Figure 1 showed the 128 [80.5\%] patients, who were placed on a definitive treatment: 19 [14.5\%] patients were on a management plan, consisting of bladder drainage and interval change of catheter: these were 11 cases of $\mathrm{BPH}, 6$ of urethral strictures, and 2 cases of hypospadias.

\section{Figure 2 : Complication after one week bladder drainage}

Figure 2: Complication after one week bladder drainage
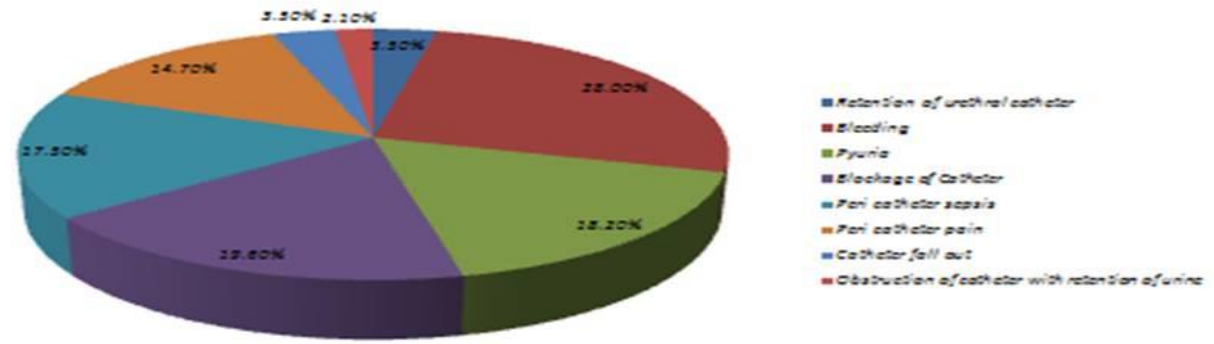
Figure 2 shows the complications resulting from prolonged catherization $\geq 7$ days. This include retention of urethral catheter, haemorrhage, catheter fall-out, urethral sepsis, pain at the catheter site and catheter obstruction. The

The co-morbid conditions seen in the patients are shown in Figure 3. Seven elderly patients, not previously diagnosed as diabetic, had a fasting following complications resulted after $\geq 7$ days of catheterization; pyuria (18.2\%), pericatheter sepsis $17.5 \%$, haemorrhage $16.8 \%$, Catheter obstruction with retention of urine $2.1 \%$, and catheter fall- out $3.5 \%$.

blood sugar level above $6.5 \mathrm{mmol} / 1$ on two occasions, and were subsequently managed as cases of type 2 diabetes.

\section{Figure 3: Associated co-morbidities}
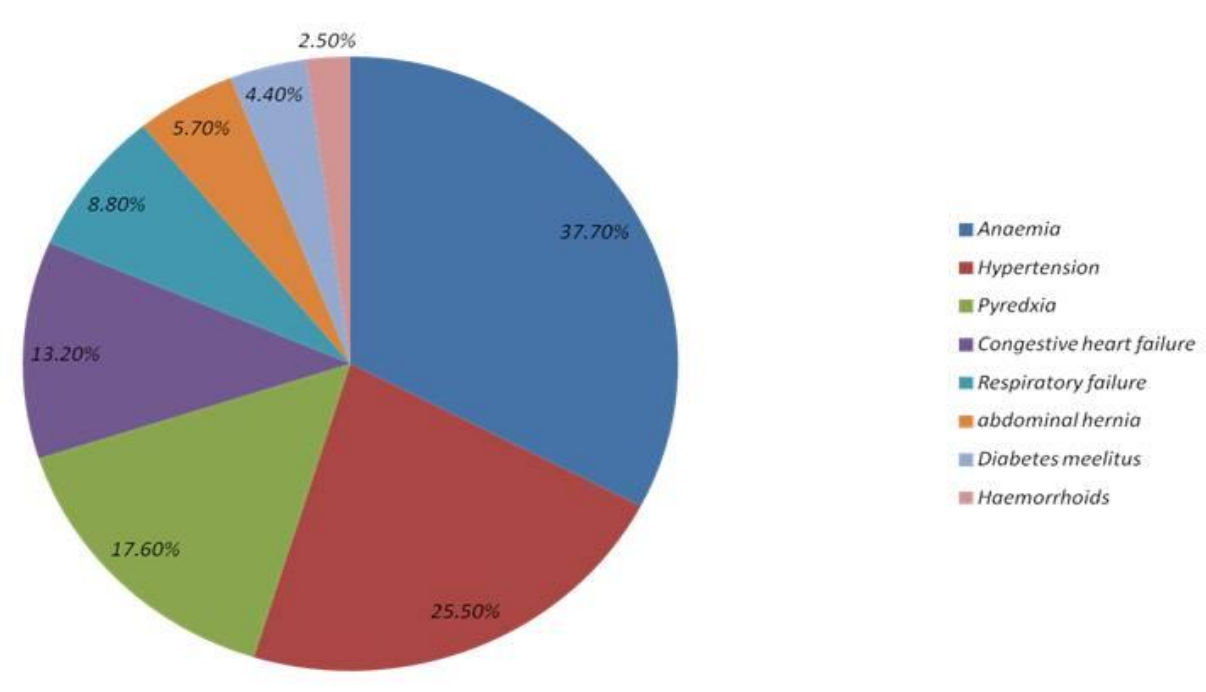

Figure 3 shows the distribution of the comorbid conditions in the cohort of patients. Anaemia and hypertension accounted for, $37.7 \%$ and $25.5 \%$ respectively; followed by fever, congestive heart failure, respiratory failure, diabetes and haemorrhoids.

\section{DISCUSSION}

The World Health Organisation [WHO] has projected a $20 \%$ increase in the cases of LUTS and bladder outlet obstruction [BOO] in Africa by the year 2018; primarily from a projected increase in the aged population (12). This and previous studies have shown that $\mathrm{BPH}$, carcinoma of the prostate and urethral stricture are the major causes of retention in this set of population $(1,5,7,11,16)$ Eight of these elderly patients in our study presented late with metastatic carcinoma of the prostate, associated with paraparesis of the lower limbs, as well as hypertension, heart failure, and diabetes. In most of the young patients $[\leq 40$ years], retention resulted mostly from urethral stricture, spinal cord injury, RTA, and urethritis [19.5\%], Table 2. These observations corroborate previous studies $(1,2,4,5$, $7,10,17)$.

The methods employed in relieving retention [Table 2] are the standard methods in current practice $(1,5,11,16,17,18,19)$; however the use of indwelling urethral catheterization to relief functional (neurogenic) retention is not a norm in current practice. Current practices are in favour of intermittent urethral catheterization, either by the patient, after a period of training or by a trained nurse $(1,17,18,21)$. The procedure however requires frequent change of catheter. This makes it difficult to practice in our setting of; limited number of staff with the requisite experience, and poor patients who may not afford the resource to provide a catheter when required. Even in societies where there is awareness to self-catheterize, there is always a need for visitation by a community nurse to ensure that instructions are followed and sterility maintained $(1,21,22)$. In our society where home visitation by trained nurses is not practiced, it will be unwise to advise even an enlightened patient to self-catheterize at home, in view of the possible complications e.g urethral trauma and endotoxic shock $(1,7)$ that can be fatal.

Twenty five [44.6\%] patients with prostatic neoplasms were placed on trial without catheter (TWOC) after three weeks of medical management. However the success of this approach could not be assessed, due to the infrequent clinic attendance by the majority of these patients. Choong et al (1) in their study of acute cases reported up to $15 \%$ success rate of TWOC in men with prostatic pathologies, with a few re-obstructing within less than 12 weeks. Thirty four patients $(21.4 \%)$ had supra pubic cystostomy [SC].These were patients who failed attempted urethral catheterization ; 14 were patients with $\mathrm{BPH}, 12$ had cancer of the prostate and 7 multiple urethral strictures on urethrogram. While in most patients with $\mathrm{BPH}$, the passage of a urethral catheter may not be problematic, however the enlargement of the median lobe, distorting the prostatic urethra, may make this difficult and traumatic, warranting a resort to suprapubic cystostomy. 
Getting antibiotic impregnated catheters and the right size of catheter based on the patient's age was difficult, Table 3. Throughout the study no antibiotic impregnated or silastic catheter was used. When small calibre catheters such as size 6 or 12 Foley were required to drain paediatric patients, we used improvised nasogastric feeding tubes of similar sizes as alternatives. This led to bed wetting with a breakdown in environmental and local hygiene around the urethral meatus, and a failure to achieve the expected clinical effects, as urinary leakage was frequently occurred. Etuknwa et al (7) and Ikuerowo et al (16) reported similar difficulties in their studies.

The use of large size Foley catheter such as size 24 , also presented serious problem; apart from urethral trauma, this size of catheter is likely to obstruct paraurethral glands, leading to peri catheter urethritis, and subsequently post catheterization urethral stricture $(1,23,24,25)$ .Even though we did not document any case of post catheterization urethral stricture in this study, this may be due to the short period of follow up.

The average catheter day of our patients was 37 days. This contrasted sharply with the reports of studies conducted in the Western societies; where catheter days ranged from 3-5 days $(1,11,17,21)$. This prolonged period of catheterization was also the finding of Awojobi and others practicing in environments similar to ours $(7,16,23)^{\circ}$ We believe that this prolonged catheterization contributed to the frequency of the complications documented in this study Figure 2; which are similar to those of these previous authors.

From the history, most patients presented in retention after several weeks or months of lower urinary tract symptoms (LUTS), which they considered unimportant. Previously authors (4, 7, $10,16,23)$ documented similar findings, and attributed this to; ignorance, poverty, the paucity of medical facilities and trained manpower in most developing societies. We believe that these observations are true, and we suggest that there is a need for health education using traditional and modern media.

Seven $(4.4 \%)$ new cases of diabetes were discovered among the elderly cohort $\left[7^{\text {th }}\right.$ decade and above]. Forty [25.2\%] of this group of patients were equally hypertensive. The combination of hypertension and diabetes as co- morbidities in elderly patients with $\mathrm{BPH}$ and $\mathrm{CaP}$ is well established $(4,5,7,10,14)$, and are currently recognised as diseases of aging, and a form of metabolic syndrome $(1,8)$. The metabolic syndrome is currently a recognised independent risk factor for poor out-comes in the management of many disease entities in clinical medicine (26). These elderly diabetics were discovered from the result of a fasting blood sugar: we have a policy of doing a fasting blood sugar for all patients in the $7^{\text {th }}$ decade and above, even if their urinalysis is normal, based on our understanding and experience ,that elderly patients may have a normal urinalysis, but with elevated blood sugar level, due to a physiologically elevated transport maximum $\left[\mathrm{T}_{\max }\right]$ of sugar in the kidneys (27) .

The incidence of urinary retention in this study was $0.23 \%\left(230 / 10^{5}\right)$, which is lower than that reported in the literature $(1,3,5,7,11,16)$. This difference may be due to the fact that these previous studies were retrospective, with the possibility of inaccurate data collection. Additionally most of the quoted studies were multicentre, and longitudinal studies.

This study showed that urinary retention is commoner in males than females, with a male: female ratio of 39:1.The incidence is highest among males in their 6th and $7^{\text {th }}$ decades of life, where the main causes are $\mathrm{BPH}$ and $\mathrm{CaP}$. Below those age bracket, trauma and infections were the common aetiologies.

The recent projected increase in lower urinary tract pathologies by 2018 , by the WHO (12), calls for a proactive approach by health planners and managers in the developing regions of the world, especially Africa. This will involve the training of personnel and the development of appropriate infrastructures. We also suggest that persons $60 y e a r s$ and above be mandatorily included in the nations' Health Insurance Schemes or similar schemes ,to facilitate their treatment whenever they present at any health care facility.

One limitation of this study is that, urinary retention was diagnosed based on clinical grounds only. Currently post void urine of up to $200 \mathrm{ml}$ and above discovered either by urethral catheterization or imaging studies is defined as retention $(1,2,11$, 14). The quoted incidence is thus relative, and may not reflect the actual situation by current definition.

\section{ACKNOWLEDGMENT}

We would like to acknowledge the Head of Department of Medical Records and his staff for helping in the retrieval of relevant clinical data. We also acknowledged Mrs. Ididiong Etim who typed the manuscript.

\section{REFERENCES}

1. Choong, S, Emberton M. Acute Urinary retention. BJU 2000; 85: 186-201.

2. Murray K. Acute retention- Urodynamic assessment BJU 1984; 56: 468-473

3. Patel R. Nitti VW. Bladder outlet obstruction in women: prevalence, recognition and management. Current Urology. 2011; 2: 379387.

4. Dawam D, Rafindadi AH, Kalayi FD. Benign Prostatic hyperplasia and prostate cancer in native Africans. BJU 2000; 85: 1074-1077.

5. Soyebi K O, Awaosanyo GOG. Causes of obstructive uropathy at the Lagos University Teaching Hospital, Lagos, Nigeria. Nigerian Journal of Hospital Medicine. 1996; 6: 173177.

6. Alan PD, Timothy JC. Diagnosis and treatment of Urological Malignancy: the prostate. British Journal of Hospital Medicine. 1996; 35: 104125.

7. Etuknwa BT. Management of Urinary retention in rural areas. Nigeria Journal of Surgical sciences 2006; 16: 31-34.

8. Kakizaki H, Koyanagi T. Current views and status on the treatment of lower urinary tract symptoms and neurological lower urinary tract dysfunction. BUJ 2000; 85; 25-30.

9. Eleftherios PD. Prostate cancer, will we win the battle in the new century. Hospimedia International 2000; 18: 25-30. 
10. Ekwere PD, Ebge SN. The changing pattern of prostate cancer; current status in the south Eastern States. Journal of the National Medical association, USA. 2002; 94: 619-627.

11. Pickard R, Emberton M, Neal DE. The management of men with acute urinary retention. BJU 1998; 81: 712-720.

12. Debra EI. Incidences and prevalence of bladder conditions.BJU 2011; 108:1132-1139.

13. Minardi D, d' Anzeo G, Cantoro D, Conti A, Muzzonigro G. Urinary tract infection in women; aetiology and treatment options. Int. J. Gen Med 2011; 4: 333-343.

14. Boyle P, Robertson C, Mazzetta C, et al. The prevalence of lower urinary tract symptoms in men and women in four centres. BJU 2003; 92: 409-414.

15. Nordling J. Altering disease progression: the key to successful patient management. BJU 2004; 93: 16-20.

16. Ikuerowo SO, Ogunade AA, Ogunlowo TO, Uzodimma CC, Esho JO. The burden of prolonged indwelling catheter after acute urinary retention in Ikeja - Lagos Nigeria. BMC Urol. 2008; 7: 16-20.

17. Fitzpatrik J M, Kirby RS. The management of acute urinary retention. $\quad B J U($ Int $) 2006,97$ : 16-20.

18. Khoubehi B, Watkin NA, Me AD, Ogden CW. Morbidity and the impact on daily activities associated with catheter drainage after acute urinary retention. BJU (int) 2000; 85: 1033 1036.

19. Drinka PJ. Complications of chronic indwelling urinary catheters. $\mathrm{J} \mathrm{Am} \mathrm{Med}$. Dir Assoc. 2006; 7: 388-392.
20. Okeke L I, Aisuiodione Shadrack OI. Selfreported QOL measures of patients with benign prostatic hyperplasia on indwelling urethral catheter. Africa J Urology. 2006; 12: 287-295.

21. Desgradchamps F, Dela Taille A, Doublet JD. The management of acute urinary retention in France; a cross sectional survey in 2,618 men with benign prostatic hyperplasia. BJU (int). 2006; 97: 727-733.

22. Schumm K, Lam TB. Strategies for the removal of short term indwelling urethral catheters in adults. Neurolal Urodyn. 2008; 27: 738-746.

23. Awojobi A. Prostatectomy in district Hospital: a preliminary report. Nigerian Medical Practitioner. 1986; 11: 101-102.

24. Trautner BW. Management of Catheter associated urinary tract infection. Curr. Opin infect Dis. 2010; 23: 76-82.

25. Emberton M, Fitzpatrick JM. The Reten world survey of the management of acute urinary retention: preliminary results. $B J U$ (int). 2008; 101 suppl 3: 27-32.

26. 26 . Gibson PR, Shepherd SJ. Personal view: food for thought-western lifestyle and susceptibility to Crohn's disease. The FODMAP hypothesis. Aliment. Pharmacol. Ther. 2005; 21: 1399-409.

27. Ganong WF. The kidneys: In Ganong W F , ed . Review of Medical Physiology. $13^{\text {th }}$ edition, Lange medical books, New York 1985: 581606. 